\title{
Using Ontologies for the E-learning System in Healthcare Human Resources Management
}

\author{
Lidia BĂJENARU ${ }^{1}$, Ana-Maria BOROZAN ${ }^{1}$, Ion SMEUREANU ${ }^{2}$ \\ ${ }^{1}$ National Institute for Research \& Development in Informatics, Bucharest, Romania \\ ${ }^{2}$ Bucharest University of Economic Studies \\ lidia.bajenaru@ici.ro,marika@ici.ro,smeurean@ase.ro
}

This paper provides a model for the use of ontology in e-learning systems for structuring educational content in the domain of healthcare human resources management (HHRM) in Romania. In this respect we propose an effective method to improve the learning system by providing personalized learning paths created using ontology and advanced educational strategies to provide a personalized learning content for the medical staff. Personalization of e-learning process for the chosen target group will be achieved by setting up learning path for each user according to his profile. This will become possible using: domain ontology, learning objects, modeling student knowledge. Developing an ontology-based system for competence management allows complex interactions, providing intelligent interfacing. This is a new approach for the healthcare system managers in permanent training based on elearning technologies and specific ontologies in a complex area that needs urgent modernization and efficiency to meet the public health economic, social and political context of Romania.

Keywords: e-Learning, Human Resource Management, Ontology, Personalization, Semantic Web

1 Introduction

This paper offers an ontology usage model in e-learning systems to structure the educational content in the domain of healthcare human resources management (HHRM) from Romania. The objective is to improve human resource (HR) knowledge, increase skills and qualifications of medical staff, ensuring personnel according to each job, in order to meet public health goals.

We propose a system for personalized learning by defining this process adapted to each person involved in health system management by using modern web-based technologies, namely ontology. This system is meant to contribute to checking knowledge and growth medical staff skills in HHRM field [1].

We present the design elements of an elearning system with application in healthcare, and the steps to make a personalized training program using also Internet resources. The e-learning system aims to:

- design and implement an e-learning environment based on web technologies, able to lead the process of building a personalized content for each learner;

- solve some current limitations of elearning systems, namely those referring to the flexibility of computer assisted learning process and the promoted teaching methods, by offering new facilities to users, such as: (1) adaptive and personalized training process, (2) providing electronic documents, bibliographies by data extraction.

Human Resource Management (HRM) aims to improve the organizational structure by increasing the performance of its members. A good HRM brings profit to the institution by the judicious use of human resources.

In this respect the major objective is to personalize the learning process using ontologies to define the human resource management domain. Personalizing learning in HRM will be achieved by setting up learning paths for each user according to his/ her profile, level of knowledge, requirements and objectives. This will become possible by using: (1) the domain ontology, (2) learning objects, (3) modeling learner's knowledge. 
Due to the rapid scientific and technological development and accumulation of new information in different fields which imply updating knowledge for the specialists, lifelong learning (LLL) is a necessity in modern society, and includes in addition to the full range of formal, informal and non-formal learning, competences, knowledge, attitudes and behaviors that people acquire in their daily life [2], [3].

In this paper we present the personalization model components, the methodologies underlying the ontology prototype, the prototype and the steps that will follow this work.

\section{E-learning}

The e-learning system assumes the existence of a learning framework (a platform), having implemented all the mechanisms and content necessary to the learning process. These systems are usually complex, require a large number of applications and resources and must ensure the communication between the training provider and the participants to the training process, and allow permanent access to the learning content and to online evaluation. E-learning is an alternative to lifelong learning in today and tomorrow informational society: the knowledge society.

The new computerized environments must support new learning paradigms such as integration of work and lifelong learning, learning on demand, self-directed learning, con- textualized information according to tasks, learning motivation, collaborative learning and organizational learning. The objectives in this area are personalized learning, educational content, widely re-usability, interoperability - ensuring communication among elearning systems, as well as with the human resources management systems.

\subsection{Personalization, an advanced approach in e-learning systems}

Lifelong learning is a systematic approach of getting and development of knowledge. Learners have different learning styles, goals and preferences, leading to variations in the efficiency and effectiveness of traditional elearning from individual to individual. Learning personalization becomes an advanced stage of the e-learning evolution.

The e-learning system proposes to implement the personalization concept and to demonstrate that the learning personalization requires new solutions for several aspects like: profile identification, users' knowledge, learning style, psychological profile, learning goal, training level, user's goal and context, knowledge formalization, user's competences, user skills level assessment and feedback. The proposed personalization model involves three main domains: (1) the modeling of teaching-learning process, (2) learner modeling and (3) digital content modeling (Figure 1) $[4]$.

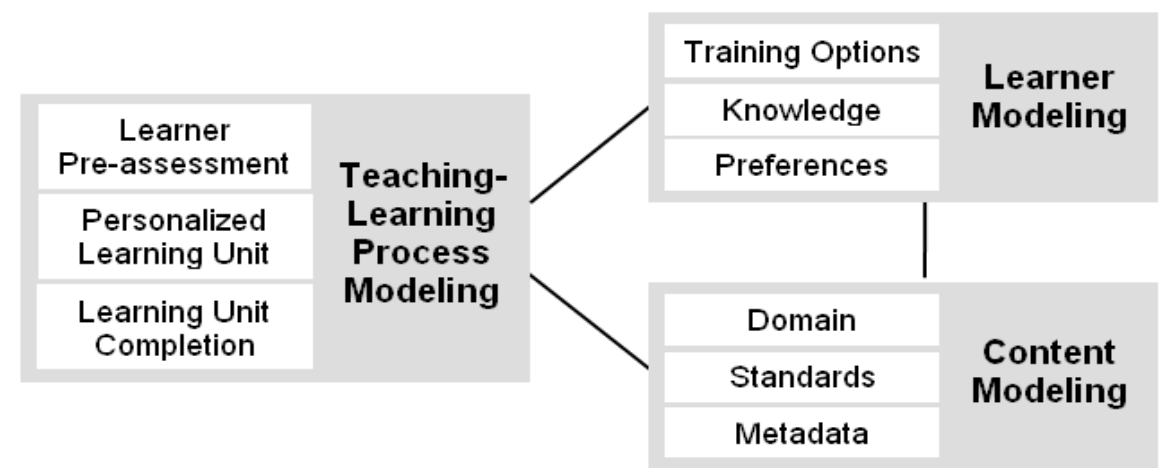

Fig. 1. Personalization support

The models are based on the use of Information Management System (IMS) standard, which offers a conceptual framework for all three mentioned areas of expertise (IMS,
1999-2013). This choice was based on a global evaluation of the existing e-learning standards (e.g. SCORM, IEEE, and IMS). 
The teaching-learning modeling process implies the evaluation of several alternatives having as objective the personalization of the content and services offered to the learner, that lead to the creation of an optimal complex scenario including several steps: (a) the specification of the personal training options (e.g. entire course, one module, competence acquirement), personal data (e.g. studies / qualifications, age, activity domain) and personal preferences (e.g. learning style, hard- ware-software support), (b) pre-assessment of the learner knowledge level according to his/ her options, (c) personalization of the learning unit (course, lesson, module etc.) based on the learner's options, knowledge level, profile and preferences, (d) learning unit completion, with specific sub-phases for a computer assisted course, (e) final assessment and course close-up. The training design specifications are the basis for the system functional model (Figure 2).

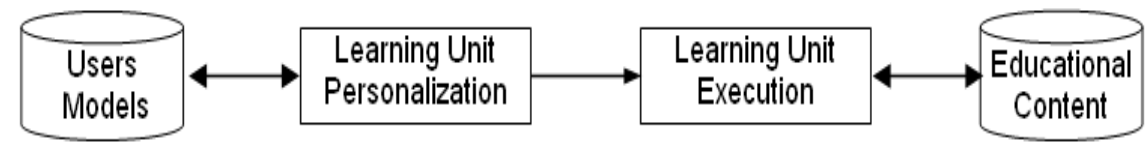

Fig. 2. Functional model

Regarding the learner model, the most complex personalization model can be achieved on five distinct levels, from simple to complex, as specified by Martinez [5]: (1) namerecognized personalization, (2) self-described personalization, (3) segmented personalization, (4) cognitive-based personalization and (5) whole-person personalization. These levels may act independently or interrelated.

For the proposed e-learning system, the personalization by name recognition, selfdescribed personalization and cognitivebased personalization will be merged and in- ter-related. The cognitive data acquisition will be made using MCQ (multiple choice questions) and psychological tests.

Several issues will be taken into account to specify the learner model: (1) personalization requirements taken from user knowledge profile that results from his/her profession, (2) IMS standard recommendations [6], (3) optimized choice of learning style according to the learners' cognitive-behavioral features. A detailed diagram of the learner data model can be represented as in Figure 3.

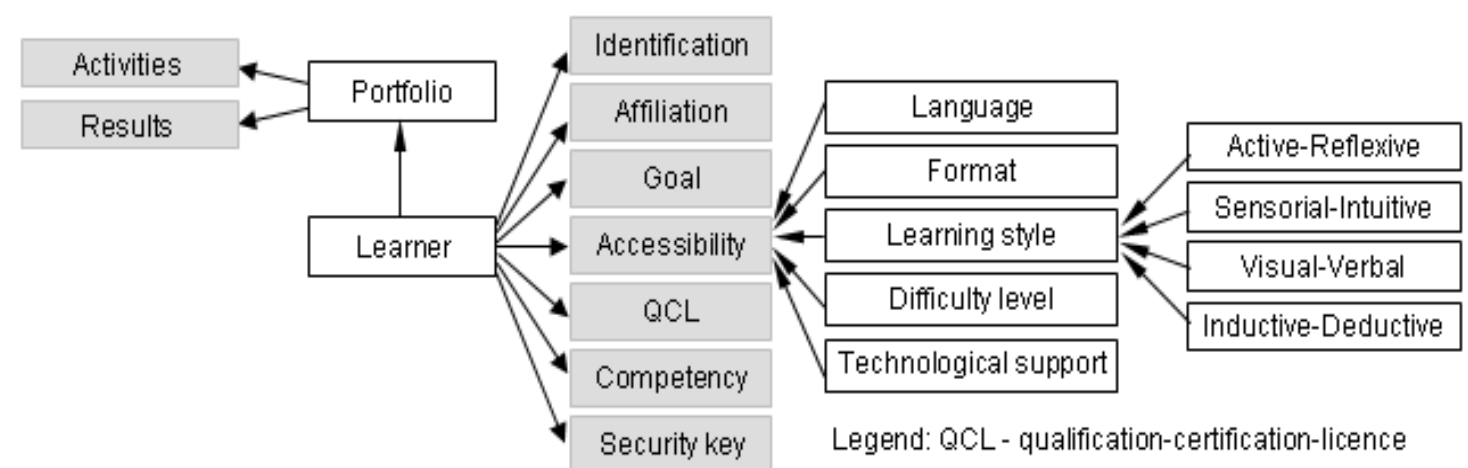

Fig. 3. Learner data model

Educational content modeling has to respond to the personalization requirements; the educational content will be structured as a collection of distinct learning objects. Their reuse in different contexts and (re)sequencing in different learning paths requires the adoption and definition of two essential elements:

- the domain ontology (the structure of concepts and the relationships among them), 
- metadata describing the properties of the learning objects.

The course ontology will be extended with the competences ontology, a structure of the educational content that enables learning of some basic concepts and certain knowledge that complement and / or support the main topic (previously studied). This approach allows a suitable training where there is no correlation between course materials and competency gap and thus provide information related to learner's requirements.

\section{Ontology}

An ontology is an efficient support for the course setting up / learning phase. An ontology is a formal representation of a common and explicit conceptualization of a domain of interest. It consists of a set of concepts (entities, attributes, properties) related to a domain, along with their definitions and relations among them. In the e-learning systems, the concept of ontology became increasingly common, aiming at: semantic interoperability of services, semantic web concept implementation, e-learning systems integration, personalization and user centered content [7], [8].

There are many solutions and research that emphasize the use of ontology in personalization modeling and e-learning environment automation, namely for: learner profile modeling, behavior assessment, describing knowledge about learning styles and other issues arising in the context of e-learning personalization [9]. According to Gruber [10]: "An ontology is the conceptualization of a knowledge domain in a format intended to be processed by computer, format modeling entities, attributes, relationships and axioms".

\subsection{Semantic Web}

Due to the large amount of information on the Web, it is very difficult for a user to reach the desired content, personalized to his knowledge level. The modern web 2.0 technologies are not effective ways to solve this problem. The solution is a new technology: the semantic Web. The term "Semantic Web" reflects a new World Wide Web (WWW) ar- chitecture that improves content with formal semantics, which provides new navigation opportunities in cyberspace "The Web will reach its full potential when it becomes an environment where data can be shared and processed by automated tools as well as by people" [11]. Semantic web is based on the following core technologies: (1) Extensible Markup Language (XML) - is a widely used language for encoding documents and representing data structures, (2) Resource Description Framework (RDF) - is a data model that is used to represent data in the semantic web and the relationship between them. $\mathrm{RDF}$ is an XML-based language that allows the description of the relations using predicates, (3) Ontology - is a key part of making intelligent semantic web. Ontologies allow users to communicate with each other by providing a common set of terms or vocabularies and rules that govern how these terms work together. The purpose of web-based ontology is to provide richer integration and interoperability of data among descriptive communities [12].

The Semantic web could be used to implement an e-learning process. "Ontologies can be used to describe: (1) the content of learning materials, (2) the pedagogical context (such as introduction, analysis, discussion) and (3) the structure (the overall set of relations among parts of a course such as previous, next, is -part-of, references and so on)" [13].

\subsection{Methods, Methodologies, Tools}

There are several methods and methodologies proposed in the literature as a guide for the main steps of ontology development cycle. In [14] there is an analysis of methodologies for building ontologies, but no one covers completely all the processes related to ontology. Most of them are focused on development activities, on ontology conceptualization and implementation.

The important aspects related to management, learning, integration, evolution and evaluation of ontologies are not specifically treated. 
The method to develop ontologies from scratch is presented in Methontology by Fernandez López et al. [15] and may be used to create domain ontologies. The Cyc method [16] is mainly oriented to support knowledge acquisition activity. The method of Uschold [17] refers to many aspects of ontology development cycle. These proposals were based on the IEEE standard for software development [18].

Tools for creating ontologies have emerged in the mid 1990s. The languages specifically designed for data are: Resource Description Framework (RDF), Web Ontology Language (OWL, http://www.w3.org/TR/owl-features/) and Extensible Markup Language (XML). Web Ontology Language (OWL) is "a Semantic Web language designed to represent rich and complex knowledge about things, groups of things, and relations among things" [19]. OWL documents, known as ontologies, can be published in the WWW. OWL enables, via XML, the description of classes that includes specific components and properties. There are more ontology design media (Protégé, Ontolingua, CommonKADS, Chimaera).

In our approach we use Protégé 2000 [20] which is a Java-based ontology editor with OWL Plugin, so it allows ontology implementation as an applet on the Web and allows multiple users to share it. We also use guidelines like in [21] to create the specific domain ontology.

\subsection{Prototype Ontology}

The approach of the proposed e-learning system will be focused on learning techniques in order to provide a structured organization of knowledge, using and extracting data from Web addressed to persons with concerns in HRM in the public health system.

The vast range of Web information makes difficult for a user to find personalized desired content. It is therefore necessary to identify a method, an automated path to search information in the proposed domain, a HRM sub-domain namely human resource management in healthcare (HHRM). The proposed ontology will represent a knowledge base of information from the HRM in a hospital. Users will interact with other courses (Web-based courses) and other personalized educational systems.

In this paper we present our intention to prepare an e-learning system addressed to users from HRM in the public healthcare system, in order to create and refine in a dynamic manner the management competences necessary in a general hospital activity.

E-learning for targeted users aims to improve performance, human resources competences and ability to assess the healthcare services provided by the hospital. The scheme of the personalized e-learning system, designed and tailored to learning requirements to define key concepts that are the bases of a performance management in the healthcare system is presented in Figure 4.

Depending on the profile and responsibilities of each management team member, they will have access to the e-learning platform, in order to obtain a personalized learning program based on a specific ontology, as well as to get bibliographies complying with their learning requirements. For example, the general manager may be a physician - then, his/her training needs will have to focus more on management issues; in other hospitals the manager may be an economist, which means an increased emphasis in his/her training process on medical issues related to the hospital functioning. It follows the importance of the personalization process, depending on the profile resulted from the basic profession, that will capitalize the already acquired knowledge to identify the most suitable learning programs which are provided by the e-learning system ontology.

In the human resources domain an important issue is competence. Competence consists of individual knowledge and skills that fit a particular job. Competence management is a process that determines the necessary human resources to achieve the organization's objectives, developing strategies for recruitment or for internal development to reach the required proficiency levels [22]. 


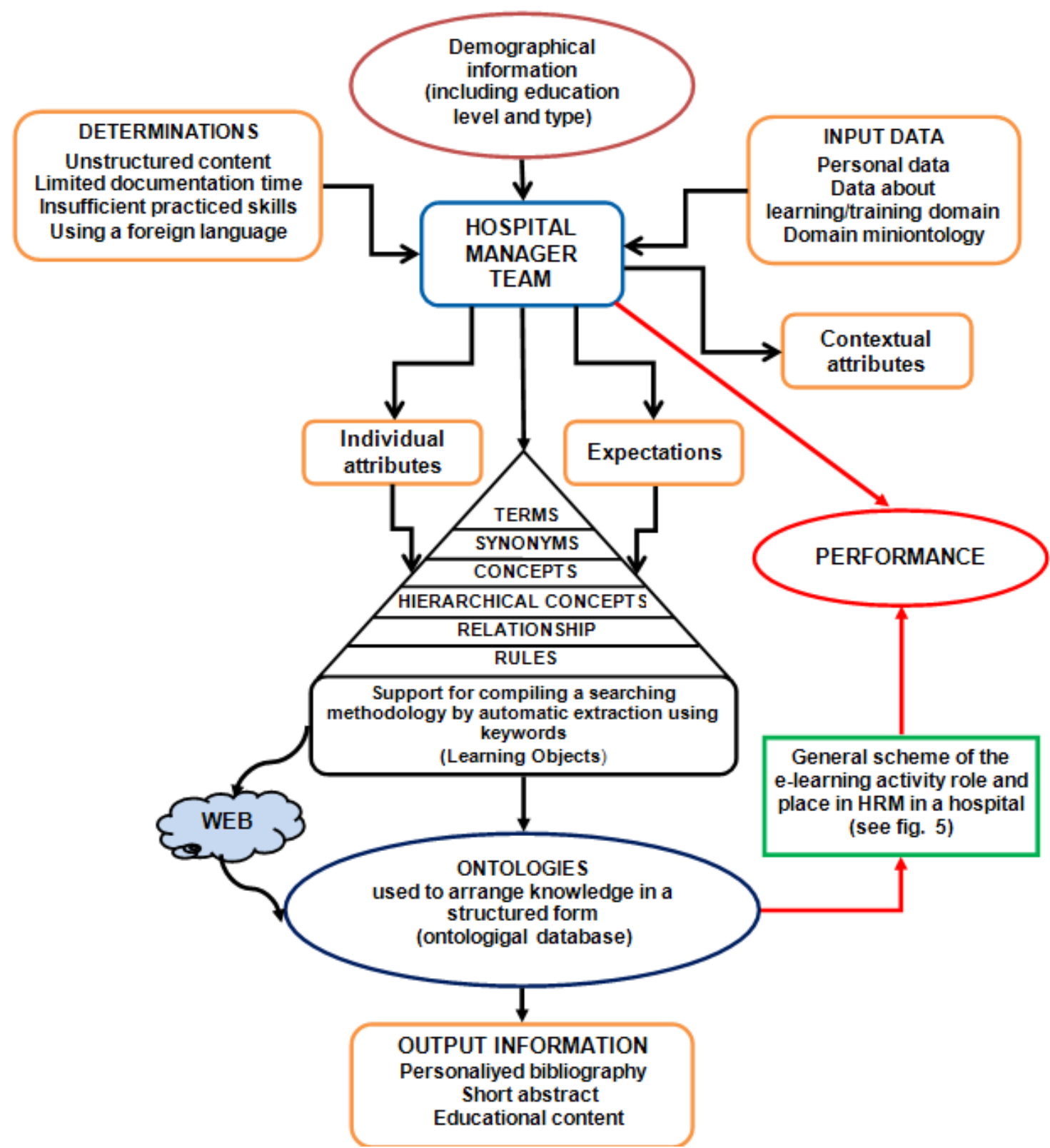

Fig. 4. General scheme of the e-learning process using ontologies

The ontological system underpinning elearning in HHRM aims: to contain a complete and systematic knowledge base about the competences of the people we address to, to provide knowledge about competences, to enable the application of available knowledge to serve the set purpose. Specific information necessary to knowledge content to be acquired, with the goal to update the permanent managerial skills will be in the following areas: general legislation (Official Monitor), financial / economic, labor code, updated legislation, rights and obligations of physicians and other professional categories, official regulations on various medical and scientific domains, guidelines, protocols, laws and rules regarding scientific and medical research, labor protection standards and other regulations.

The sources of these information will be acquired from-specific websites (Ministry of Health, National Health Insurance House, etc.), but also from books and other educational documents.

The improvement of e-learning system users' ability in the following evaluation directions will be considered as a first step of this learning / assessment process: staffing, the rela- 
tionship between the hospital structure and staffing, the relation between the services demand and staffing, medical personnel migration, as well as methods to increase professional / hospital performance and motivation / stimulation of the medical staff.

Based on the results of this stage, learners will be able to grasp with better competence the evaluation of healthcare services provided by hospital.

These evaluation results (in the e-learning process, based on data provided by specific ontologies) will increase managerial performance in HRM, which will be reflected in a better functioning of all services (medical, administrative-economic) from the functional structure of the hospital, aiming to increase the overall performance of the hospital. By this feedback (see Figure 5) a dynamic cycle will be closed, which involves on the one hand the inter-relation between the hospital as the central element and the health system authorities (Ministry of Health, Health Insurance System, Romanian College of Physicians, etc.), and on the other hand the continuous increase of hospital medical activity efficiency through a better and permanently adapted management to the medical system evolution in all aspects: scientific, technological, economic, legal, administrative.

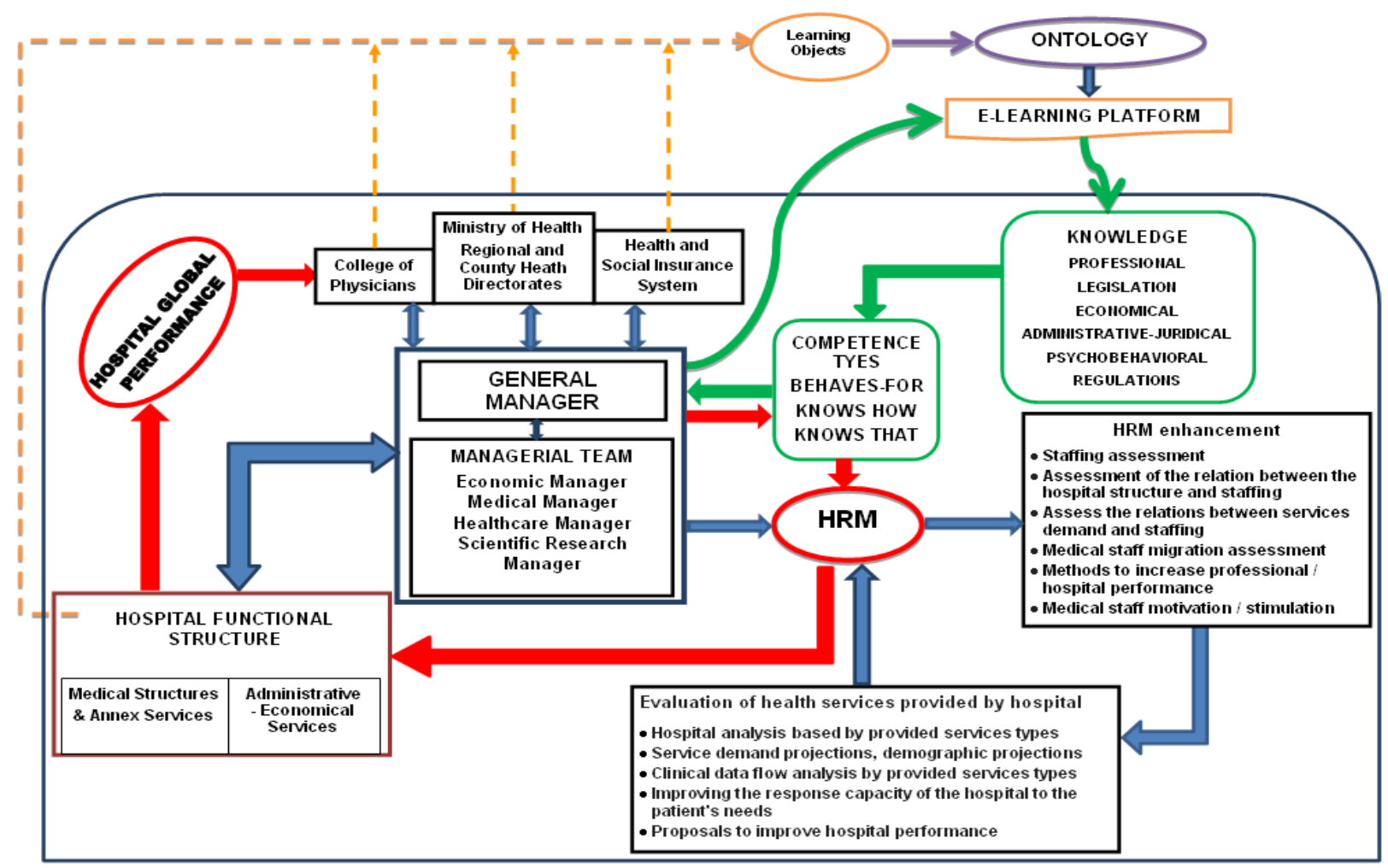

Fig. 5. General scheme of the e-learning activity role and place in HRM in a hospital

Protégé environment is used to develop the knowledge base of HRM domain, the basic concepts and their relationships. Thus the HRM concepts' hierarchy, in tree format and in graphic format, is shown in Figure 6, 7.

The proposed e-learning platform, based on semantic web technology, provides electronic tools necessary to implement a new mechanism to obtain relevant information from the Internet, offering a the possibility to use the advantage of the semantic web and multimedia content (documents in electronic format, links, pictures, animations, sound, video, etc.). The platform will enable a "live" link of the trainer with the target group through specific subcomponents (e.g. Forum, internal messaging). Processing and collection of information specific to semantic web will be executed by a module / sub-component using open source RDF and OWL language. 


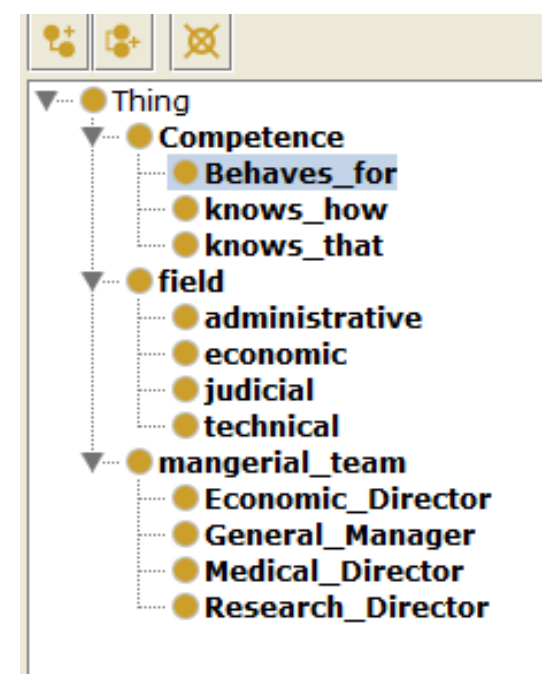

Fig. 6. Basic concepts of ontological system for HRM in a hospital

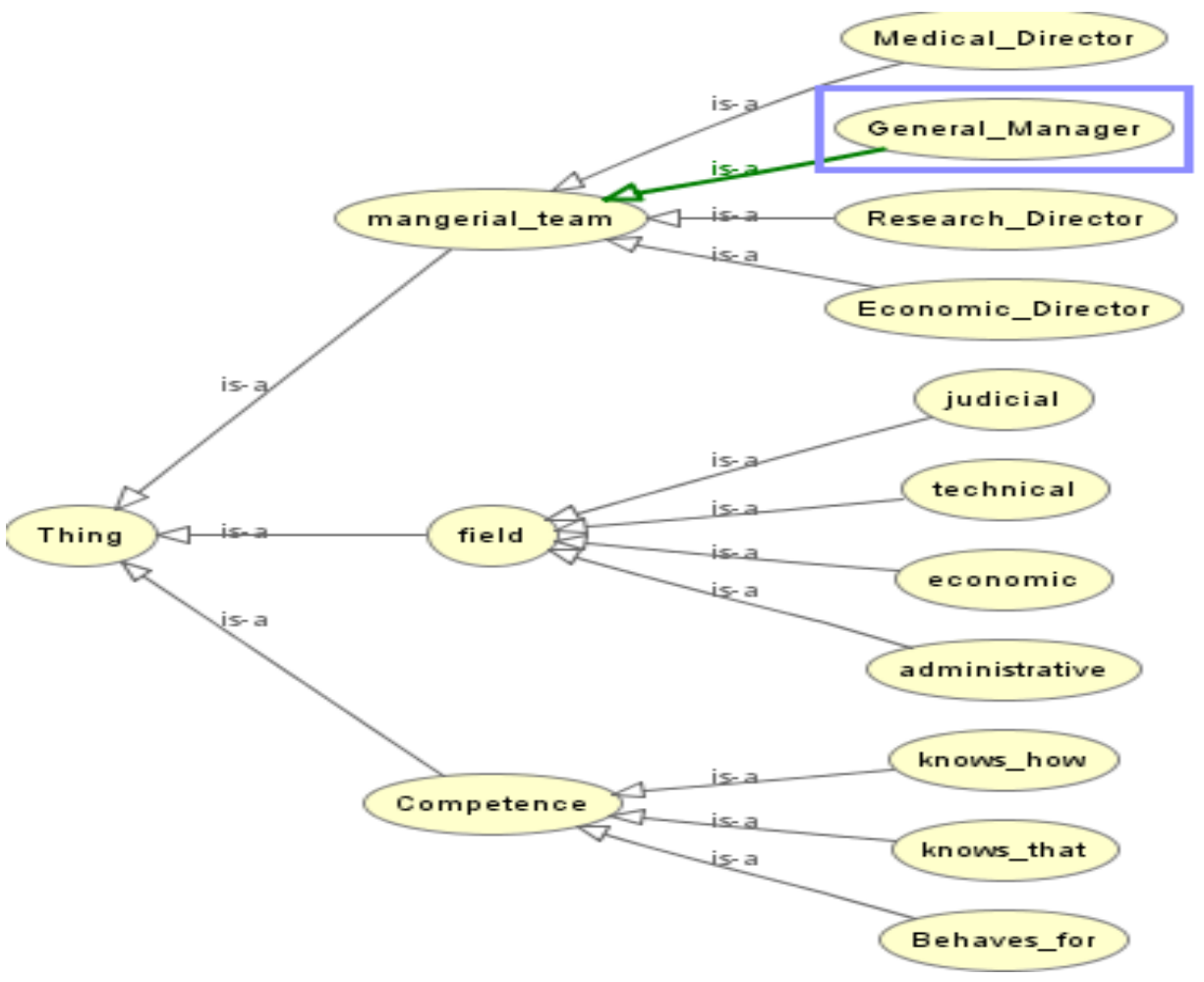

Fig. 7. Part of the ontological system for HRM in a hospital

\section{Conclusions}

In this ontology-based approach, the design of a personalized e-learning system in HHRM helps to guide attention from a function and tools oriented approach to a semantic oriented one. Developing an ontologybased system for competence management allows complex interactions, providing intelligent interfacing.
This paper will be followed by a knowledge acquisition phase, to collect the relevant information required to the ontology conceptualization, which will underpin the creation of a knowledge base of the multiple areas of interest. Data collection sources may be the representative employees from a hospital, and the electronic documents related to the employees skills assessed by test questions or other means. We will pay attention to the fact 
that knowledge (or meta-knowledge) will be built related to the workers' level of competence.

The conceptualization phase will follow, when the ontology will be developed. On the one hand, this model includes a conceptual system of the domain (terminology) and on the other hand, it contains rules to interpret and use the identified concepts.

\section{Acknowledgement}

A short form of this paper was presented at the 13th International Conference on Informatics in Economy (IE 2014), may 15-18, 2014.

\section{References}

[1] L. Băjenaru, A.-M. Borozan and I. Smeureanu, "An Ontology Based Approach for E-Learning in Health Human Resources Planning", Proceeding of The 13th International Conference on Informatics in Economy, 2014, pp. 352-357, ISSN: 2247-1480.

[2] I. Smeureanu, A. Dioşteanu, "A Collaborative System Software Solution for Modeling Business Flows Based on Automated Semantic Web Service Composition”, Informatică Economică Journal, vol. 13, no. 2, 2009.

[3] M. Laal, P. Salamati, "Lifelong learning; why do we need it?", Procedia - Social and Behavioral Sciences 31, 2012, pp. 399-403.

[4] I. Trandafir, A. Borozan, A. Balog , "Learning Personalization, Design Solutions In An E-Learning System", WEBIST: 4th International Conference on Web Information Systems \& Technologies, 2008, ISBN: 978-989-8111-29-6.

[5] M. Martinez, "Designing Learning Objects to Personalize Learning", 2000, Available:

http://www.reusability.org/read/chapters/ martinez.doc.

[6] IMS Global Learning Consortium, 19992014. Available: http://www.imsglobal.org/

[7] A. De Nicola, M. Missikoff, F. Schiappelli, "Towards an Ontological
Support for eLearning Courses", WOSE Workshops. Cyprus, 2004.

[8] O. Corcho, M. Fernández-López, A. Gómez-Pérez, "Ontological Engineering: What are Ontologies and How Can We Build Them?" In Cardoso J editor. Semantic Web Services: Theory, Tools and Applications; IGI Global (former Idea Group). Hersey, Pennsylvania, USA, 2007, pp. 44-70.

[9] M. Ivanova, M. A. Chatti, "Defining Ontology Specification for Personal Learning Environment Forming" Proceedings of the ICL2010. Hasselt, Belgium, 2010.

[10] T. R. Gruber, "A translation approach to portable ontologies", Knowledge Acquisition, 5, no. 2, 1993, pp. 199-220.

[11] T. Berners-Lee, E. Miller, "The Semantic Web lifts off", Special issue of ERCIM New. 51. 9, 2002.

[12] T. Berners-Lee, J. Hendler, O. Lassila, "The Semantic Web", Scientific American, 284(5), 2001, pp 34-43.

[13] L. Stojanovic, S. Staab, R Studer, "Elearning based on the Semantic Web", Proc. WebNet2001 - World Conference on the WWW and Internet, Orlando, Florida, USA, 2001.

[14] M. Fernández-López, A. GómezPérez, "Overview and analysis of methodologies for building ontologies", The Knowledge Engineering Review, 17 no. 2, 2002, pp. 129-156.

[15] M. Fernández-López, A. GómezPérez, N. Juristo, "Methontology: From ontological art towards ontological engineering" Paper presented at the Spring Symposium on Ontological Engineering of AAAI, 1997, pp. 33-40.

[16] D.B. Lenat, R.V. Guha, "Building large knowledge-based systems: Representation and inference in the cyc project”, Boston: Addison-Wesley, 1990.

[17] M. Uschold, M. King, "Towards a methodology for building ontologies", In D. Skuce (Ed.), IJCAI'95 Workshop on Basic Ontological Issues in Knowledge Sharing, 1995, pp. 6.1-6.10, Montreal, Canada. 
[18] IEEE standard for developing software life cycle processes (Std 10741995). New York: IEEE Computer Society, 1996.

[19] Semantic Sea Ice Interoperability Initiative. Available: http://nsidc.org/ssiii/ontologydefinition.html.

[20] N. F. Noy, R. W. Fergerson, A. Mark, M. A Musen," The knowledge model of Protégé-2000: combining interoperability and flexibility", 2000.
[21] N.F. Noy \& D.L. McGuinness, "Ontology Development 101: A Guide to Creating Your First Ontology". Available:

http://protege.stanford.edu/publicatio ns/ontology_development/ontology10 1-noy-mcguinness.html

C. Niculescu, S. Trăuşan-Matu, "An Ontology-centered Approach for Designing an Interactive Competence Management System for IT Companies", Informatica Economică, vol. 13, no. 4, 2009.

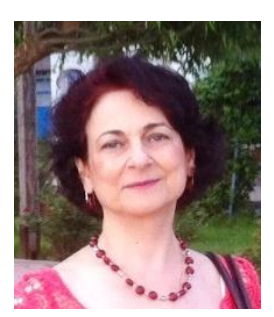

Lidia BĂJENARU has graduated the Faculty of Electrical Engineering at the Polytechnic University "Gh. Asachi" Iaşi, Automatics and Computers Section in 1985. She is PhD student at the Bucharest University of Economic Studies. Currently she is Senior Analyst 1st degree, Head of the National Software Library at The National Institute for Research \& Development in Informatics (ICI) Bucharest. After 17 years of specific training activities as expert IT trainer at Informatics Training Centre Bucharest and research in computer science, she joined ICI staff to continue her work in informatics research, systems analysis, systems maintenance and operation, software quality, upgrading and operation of databases. She is co-author of books and author, co-author of journal articles in the IT field. Her work focuses on the analysis of quality of software applications, ontologies in computer science, elearning, collaborative platforms and internet technologies.

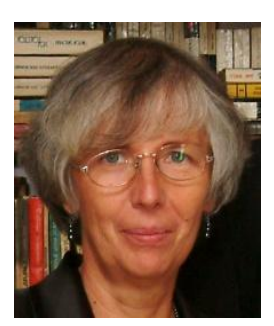

Ana-Maria BOROZAN was a Senior Engineer in the National Institute for R\&D in Informatics (ICI). She holds a M.E. in Computer Science from the University "Politehnica" of Bucharest. She has an extensive experience in the management, administration and development of projects related to the Internet service development, with as main goals software development, system management and awareness activities and WWW applications development.

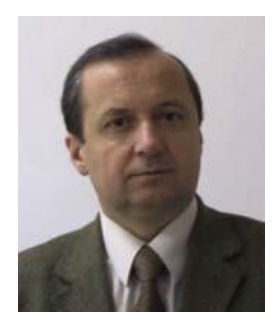

Ion SMEUREANU has graduated the Faculty of Economic Cybernetics in 1980, as promotion leader. He holds a PhD diploma in "Economic Cybernetics" from 1992 and has a remarkable didactic activity since 1984, when he joined the staff of Bucharest University of Economic Studies. Currently, he is a full Professor of Economic Informatics within the Department of Economic Informatics and the dean of the Faculty of Cybernetics, Statistics and Economic Informatics. He is the author of more than 16 books and an impressive number of articles. He was also project coordinator or member in many national and international research projects. He was awarded the Nicolae Georgescu-Roegen diploma, the General Romanian Economist Association Excellence Diploma and many others. 